\title{
High-throughput Luminex xMAP assay for simultaneous detection of antibodies against rabbit hemorrhagic disease virus, Sendai virus and rabbit rotavirus
}

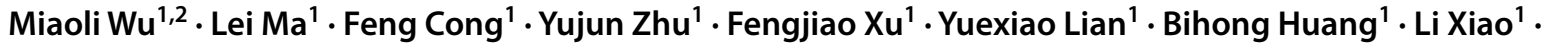 \\ Meili Chen ${ }^{1} \cdot$ Yu Zhang ${ }^{1} \cdot$ Ren Huang ${ }^{1} \cdot$ Pengju Guo ${ }^{1}$
}

Received: 13 November 2018 / Accepted: 1 March 2019 / Published online: 15 April 2019

(c) Springer-Verlag GmbH Austria, part of Springer Nature 2019

\begin{abstract}
Rabbits are widely used as models in biological research, and the pathogen status of rabbits used in studies can directly affect the results of experiments. Serological surveillance is the common monitoring method used in laboratory animals. A rapid, sensitive, and cost-effective high-throughput Luminex XMAP assay could be an attractive alternative to labor-intensive enzyme-linked immunosorbent assay (ELISA) methods. In this study, recombinant proteins from rabbit hemorrhagic disease virus and rabbit rotavirus and whole viral lysates of Sendai virus were used as coating antigens in an xMAP assay for the simultaneous detection of antibodies against these pathogens. The XMAP assay showed high specificity, with no cross-reaction with other pathogens. The coefficient of variation for intra-assay and inter-assay comparisons was less than $3 \%$ and $4 \%$, respectively, indicating good repeatability and stability of the assay. The xMAP assay exhibited similar limits of detection for rabbit hemorrhagic virus and Sendai virus and was less sensitive for the detection of rabbit rotavirus when compared with commercial ELISA kits. A total of 52 clinical samples were tested simultaneously using both the xMAP assay and ELISA kits. The results obtained using these two methods were $100 \%$ coincident. In summary, the novel xMAP assay offers an alternative choice for rapid and sensitive high-throughput detection of antibodies in rabbit serum and can be used as a daily monitoring tool for laboratory animals.
\end{abstract}

\section{Introduction}

An appropriate animal model is crucial for mimicking disease conditions, and domestic rabbits (Oryctolagus cuniculus) play an important role in biological research. Since the 1980s, rabbits have been used extensively as models of human T-lymphotropic virus type 1 (HTLV-1) infection because of the consistency of viral infection and

Handling Editor: William G Dundon.

Electronic supplementary material The online version of this article (https://doi.org/10.1007/s00705-019-04226-9) contains supplementary material, which is available to authorized users.

Pengju Guo

vetbio2016@hotmail.com

1 Guangdong Laboratory Animal Monitoring Institute, Guangzhou 510633, China

2 Guangdong Key Laboratory of Laboratory Animals, Guangzhou, China transmission in them [1]. The unique features of their lipoprotein metabolism and their sensitivity to cholesterol in their diet make rabbits a perfect model for human atherosclerosis [2] Transgenic rabbits expressing human CD4 and CCR5 homologs can be made highly susceptible to human immunodeficiency virus type 1 (HIV-1) infection and thus appropriate as models for studying disease development [3] . Rabbits are also widely used in pharmaceutical research and production of antibodies. Therefore, the quality control of rabbits is essential to guarantee the accuracy and reliability of the experiments that are performed on them.

Testing for rabbit hemorrhagic disease virus (RHDV), rabbit rotavirus (RRV), and Sendai virus (SV) is required by the national quality standards of China. Seroprevalence studies and serosurveillance are essential tools for monitoring diseases as well as vaccination efficiency [4]. Currently, the main methods for antibody detection are the enzyme-linked immunosorbent assay (ELISA) and immunofluorescence assay (IFA), which are time-consuming and labor-intensive $[5,6]$. Both are single-analyte technologies that fail to meet the high-throughput test requirements of routine quality 
monitoring [7]. Additionally, the enzyme-mediated amplification of signal during ELISA is not always linear and can thus skew the results [8]. It is therefore imperative to develop a rapid and sensitive high-throughput assay for simultaneous analysis of RHDV-, SV- and RRV-specific antibodies in a single biological sample.

The Luminex xMAP technology $(x=$ analyte, $\mathrm{MAP}=$ multi-analyte profiling) (Luminex Crop., Austin, TX, United States) invented in the late 1990s is a high-throughput bioassay platform that enables rapid, cost-effective, and simultaneous analysis of multiple analytes of interest in one sample [9]. Changes in the concentrations of two or three dyes inside an individual bead can be recognized by the red classification laser based on its spectral signature, while the green reporter laser recognizes the fluorescent reporter bound to the captured analytes on the microsphere surface. Briefly, fluorescent microspheres that are pre-coated with specific diagnostic antigens that capture the corresponding antibodies are combined with fluorescent reporters, which are recognized by the Luminex reader, which can identify up to 500 targets in a single panel $[10,11]$. In recent years, the Luminex bead system has found many applications in areas of fundamental and applied diagnostic studies [12-14].

In this study, a rapid Luminex xMAP panel was developed for simultaneous detection of specific antibodies against RHDV, SV and RRV. The performance of the XMAP assay was evaluated by comparison with a commercial ELISA kit.

\section{Materials and methods}

\section{Virus and serum samples}

Sendai virus (ATCC VR-105) was cultured in Vero cells and purified by sucrose density gradient centrifugation [15]. Negative serum from SPF rabbits and positive sera containing neutralizing antibodies against different rabbit pathogens (RHDV, $\mathrm{SV}, \mathrm{RRV}$, rabbit coronavirus [RCoV], Encephalitozoon cunic$u l i$ ) were purchased from VRL Laboratories (Suzhou, China). Fifty-two clinical serum samples were obtained from a rabbit farm in Shandong province. All purified virus and serum samples were stored at $-80{ }^{\circ} \mathrm{C}$ before use.

\section{Expression and purification of recombinant proteins}

The recombinant proteins VP60 of RHDV and VP6 of RRV were produced and purified using a prokaryotic expression system. Briefly, gene segments encoding full-length VP60 of RHDV (primers: F1, GCCGAATTCATGGAGGGCAAA GCCCGTGCAGCAC; F2, GCCGTCGACATAAGAGAA ACCATTAGCTG) and a portion of VP6 of RRV (primers: F3, GCCGAATTCATGGATGTCCTTTATTCTTTGACA; F4, GCCGTCGACGAATGCTCAACCATTTCAGC) were amplified and cloned into the plasmid vectors vector pET28a and introduced into Escherichia coli BL21 strain (TransGen Biotech, Beijing, China) by transformation. Gene expression from positive clones was induced by addition of $1 \mathrm{mM}$ isopropyl $\beta$-D-1-thiogalactopyranoside (IPTG) to the final concentration $0.1 \%$. After 6 hours of cultivation at $37{ }^{\circ} \mathrm{C}$, the expression products were purified from inclusion bodies, which were lysed using bacterial lysis buffer $(20 \mathrm{mM}$ Tris$\mathrm{HCl}, 500 \mathrm{mM} \mathrm{NaCl}, 2 \%$ Triton-X 100, pH 8.0). After sonication and centrifugation, the precipitate was re-suspended in $8 \mathrm{M}$ urea and then purified by nickel column affinity chromatography following the manufacturer's instructions. Recombinant proteins were refolded in a linear gradient of 8-0 $\mathrm{M}$ urea and identified by SDS-PAGE.

\section{Coupling of antigens to fluorescent beads}

The recombinant proteins were desalted by gel filtration using Micro Bio-Spin 6 chromatography (Bio-Rad, California, USA) according to the manufacturer's protocol to remove sodium azide or imidazole. All antigens were quantified using a Pierce BCA Protein Quantification Kit (Thermo Scientific, Rockford, IL, USA) and then conjugated to the surface of the fluorescent magnetic beads (Luminex, USA). The coupling was carried out as described by Karanikola et al. [16]. Twenty $\mu \mathrm{L}$ of magnetic beads (about $1.25 \times 10^{6}$ beads) was transferred to a low-adsorption reaction tube and placed into the magnetic separator for $30 \mathrm{~s}$, followed by centrifugation to remove the supernatant.

To activate the microspheres, $10 \mu \mathrm{L}$ of $50 \mathrm{mg} /$ $\mathrm{ml} \mathrm{N}$-(3-dimethylaminopropyl)-N'-ethylcarbodiimide hydrochloride (EDC) (Sigma-Aldrich, Germany) and $10 \mu \mathrm{L}$ of $50 \mathrm{mg} / \mathrm{ml}$ N-hydroxysulfosuccinimide sodium salt (S-NHS) (Sigma-Aldrich, Germany) were added to $80 \mu \mathrm{L}$ of resuspended microspheres and agitated for $20 \mathrm{~min}$ at room temperature. The conjugation between antigen and activated microspheres was carried out at room temperature on a shaker for 2 hours. The coupled beads were finally resuspended in storage buffer (phosphate-buffered saline [PBS], pH 7.4, with $0.05 \%$ Tween $20,0.05 \%$ sodium azide and $1 \%$ bovine serum albumin [BSA]) and stored at $4{ }^{\circ} \mathrm{C}$ in the dark.

\section{Luminex xMAP assay}

The assay was performed in a 96-well polystyrene microplate (Thermo Scientific, Rockford, IL, USA). The coupled bead sets and the relevant positive and negative control sera were diluted with PBS containing $0.05 \%$ Tween 20 and $1 \%$ BSA (PBS-TB, pH 7.4) for the establishment of single xMAP assays to detect antibodies against RHDV, SV, and RRV respectively. Briefly, $50 \mu \mathrm{L}$ of magnetic beads (50 beads $/ \mu \mathrm{L}$ ) was mixed with $50 \mu \mathrm{L}$ of diluted serum and transferred to the wells of the plate. After 60 min of incubation on 
a plate shaker $(800 \mathrm{rpm})$, the plate was carefully washed 3 times with $100 \mu \mathrm{L}$ of PBS-TB per well, followed by incubation with $100 \mu \mathrm{L}$ of PE-conjugated goat anti-rabbit IgG per well (Sangon Biotech, Guangzhou, China) for $30 \mathrm{~min}$. After the final washing step, $100 \mu \mathrm{L}$ of assay buffer was added to each well, and the plate was shaken for approximately $10 \mathrm{~s}$ and then analyzed using the Luminex reader according to the manufacturer's protocol. The whole procedure was carried out at room temperature in the dark, and all of the samples were tested in triplicate.

\section{Optimization of the assay}

The recombinant VP60 and VP6 proteins and the purified virus particles of SV were coupled with magnetic microspheres at the ratios $2.5 \mu \mathrm{g}, 5 \mu \mathrm{g}, 10 \mu \mathrm{g}, 20 \mu \mathrm{g}, 30 \mu \mathrm{g}$, and $40 \mu \mathrm{g}$ per $1 \times 10^{6}$ beads to determine the optimal antigen concentration. Each concentration was tested in triplicate, and the whole assay was carried out in duplicate.

\section{Evaluation of specificity and sensitivity}

The specificity of the test was evaluated by testing positive control antisera against RHDV, SV, RRV, RCoV, and E. cuniculi, and the sensitivity of the XMAP assay and that of the ELISA were compared using relevant positive viruscontaining sera (twofold serial dilution from 1: 100 to 1: 25600 in PBS-TB).

\section{Data processing}

Median fluorescence intensity (MFI) values and associated standard deviations were calculated using xPONENT3.01 software. The cutoff value was the average MFI value for the negative samples plus three times the standard deviation.
The cutoff value differed for each antigen, and therefore, the threshold for the limit of detection (LOD) was set based on the MFI value of the corresponding negative control serum.

\section{Results}

\section{Selection of the optimum antigen concentration}

Monoplex assays were developed to determine the optimal antigen concentration of each individual pathogen. The recombinant proteins VP60 and VP6 were tested at the ratios of $2.5 \mu \mathrm{g}, 5 \mu \mathrm{g}, 10 \mu \mathrm{g}, 20 \mu \mathrm{g}, 30 \mu \mathrm{g}$, and $40 \mu \mathrm{g}$ per $1 \times 10^{6}$ beads, while the ratio for SV virus particles ranged from $2.5 \mu \mathrm{g}$ to $50 \mu \mathrm{g}$ per $1 \times 10^{6}$ beads. A ratio of $10 \mu \mathrm{g}$ of VP60 per $1 \times 10^{6}$ beads yielded the highest positive MFI values along with the lowest negative MFI values (Table 1). For both VP6 and SV, the optimal ratio was $30 \mu \mathrm{g}$ of antigen per $1 \times 10^{6}$ beads (Tables 2 and 3), indicating that the optimal coupling ratio was $10 \mu \mathrm{g}$ per $1 \times 10^{6}$ beads for RHDV, and $30 \mu \mathrm{g}$ per $1 \times 10^{6}$ beads for both RRV and SV.

\section{Establishment of the multiplex xMAP assay}

A multiplex assay was performed as described above using the optimal antigen concentrations. Positive sera containing the three pathogens to be tested were mixed together and tested using the newly developed assay. Each sample was tested in triplicate, and the results showed that all three targets were recognized in the same sample (Fig. 1). With a standard deviation less than 300 for positive samples and less than 50 for negative samples, the assay possessed good repeatability between duplicate wells.
Table 1 The MFI values for different coating concentrations of RHDV

\begin{tabular}{llllllll}
\hline Sample type & $\begin{array}{l}\text { Serum number } \\
\text { or dilution }\end{array}$ & \multicolumn{7}{l}{ Antigen concentration $\left(\mu \mathrm{g} / 1 \times 10^{6}\right.$ beads $)$} \\
\cline { 3 - 8 } & & 2.5 & 5 & 10 & 20 & 30 & 40 \\
\hline Positive control serum & $1: 100$ & 11845 & 13687 & 15032 & 14864 & 14954 & 1432 \\
& $1: 400$ & 9964 & 10554 & 11465 & 11075 & 11764 & 10056 \\
& $1: 800$ & 8011 & 8084 & 8243 & 7942 & 8213 & 8321 \\
& $1: 1600$ & 6216 & 6344 & 6784 & 6384 & 6583 & 6534 \\
& $1: 3200$ & 2864 & 3054 & 3298 & 3086 & 3174 & 3285 \\
Blank control & $1: 6400$ & 2106 & 2321 & 2321 & 2165 & 2275 & 2203 \\
Negative control serum & PBS & 107 & 116 & 185 & 195 & 118 & 224 \\
& 1 & 229 & 264 & 237 & 226 & 289 & 263 \\
& 2 & 286 & 374 & 249 & 216 & 345 & 294 \\
& 3 & 225 & 241 & 204 & 256 & 275 & 232 \\
Negative control average & 4 & 196 & 205 & 224 & 254 & 216 & 217 \\
\hline
\end{tabular}


Table 2 The MFI values for different coating concentrations of SV

Table 3 The MFI values for different coating concentrations of RRV

Fig. 1 Establishment of the multiplex xMAP assay. 1 :RHDV positive serum; 2 :SV positive serum; 3 : RRV positive serum; 4: RHDV and SV positive serum; 5: RHDV and RRV positive serum; 6: SV and RRV positive serum; 7: triple positive serum; NC: negative control serum; Blank: blank control

\begin{tabular}{llllllll}
\hline Sample type & $\begin{array}{l}\text { Serum number } \\
\text { or dilution }\end{array}$ & \multicolumn{7}{l}{ Antigen concentration $\left(\mu \mathrm{g} / 1 \times 10^{6}\right.$ beads $)$} \\
\cline { 3 - 8 } & & 2.5 & 5 & 15 & 30 & 40 & 50 \\
\hline Positive control serum & $1: 100$ & 15007 & 17564 & 21146 & 24928 & 24033 & 22067 \\
& $1: 400$ & 9884 & 11534 & 12089 & 16417 & 15336 & 15694 \\
& $1: 800$ & 7843 & 9773 & 12199 & 12789 & 10916 & 8105 \\
& $1: 1600$ & 6867 & 7315 & 7974 & 9567 & 8042 & 6783 \\
& $1: 3200$ & 4521 & 4966 & 6963 & 7544 & 6161 & 4885 \\
& $1: 6400$ & 2485 & 3043 & 3908 & 4698 & 3960 & 3068 \\
Blank control & $1: 12800$ & 1104 & 1204 & 2013 & 2213 & 1194 & 1326 \\
Negative control serum & PBS & 89 & 109 & 114 & 121 & 154 & 173 \\
& 1 & 132 & 150 & 175 & 139 & 185 & 184 \\
& 2 & 112 & 232 & 123 & 152 & 216 & 302 \\
& 3 & 134 & 247 & 185 & 95 & 162 & 174 \\
Negative control average & 4 & 85 & 79 & 114 & 89 & 184 & 185 \\
& 5 & 159 & 158 & 188 & 101 & 174 & 184 \\
& & 124.4 & 173.1 & 157 & 115.2 & 184.2 & 205.8 \\
\hline
\end{tabular}

\begin{tabular}{llllllll}
\hline Sample type & $\begin{array}{l}\text { Serum number } \\
\text { or dilution }\end{array}$ & \multicolumn{7}{l}{ Antigen concentration $\left(\mu \mathrm{g} / 1 \times 10^{6}\right.$ beads $)$} \\
\cline { 3 - 8 } & & 2.5 & 5 & 10 & 20 & 30 & 40 \\
\hline Positive control serum & $1: 100$ & 13282 & 14674 & 16483 & 17535 & 18736 & 18324 \\
& $1: 400$ & 8754 & 9964 & 12194 & 12343 & 13542 & 12965 \\
& $1: 800$ & 7643 & 8084 & 10563 & 10321 & 11043 & 10764 \\
& $1: 1600$ & 6496 & 6984 & 7554 & 7756 & 8352 & 8143 \\
& $1: 3200$ & 3569 & 3947 & 4576 & 4776 & 5213 & 5027 \\
Blank control & $1: 6400$ & 2435 & 2984 & 3654 & 3854 & 4034 & 3886 \\
Negative control serum & 1 & 138 & 156 & 189 & 205 & 158 & 232 \\
& PBS & 158 & 184 & 174 & 146 & 175 & 224 \\
& 2 & 121 & 158 & 112 & 253 & 124 & 253 \\
& 3 & 206 & 252 & 194 & 196 & 164 & 194 \\
Negative control average & 4 & 227 & 243 & 221 & 275 & 205 & 206 \\
\hline
\end{tabular}

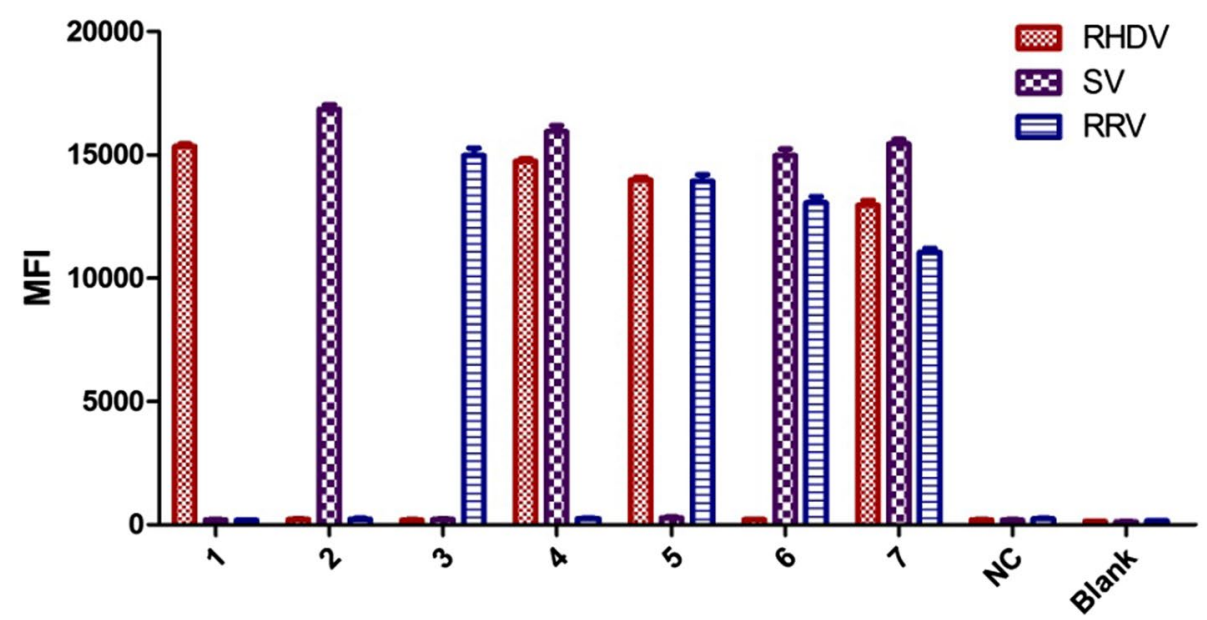




\section{Specificity of the multiplex xMAP assay}

Positive virus-containing sera were used to evaluate the specificity of the XMAP assay. Each sample was tested in triplicate, and significant specific signals were observed only with the positive samples and no obvious cross-reactions were observed with irrelevant samples (Fig. 2).

\section{Determination of cutoff values}

The cutoff value was determined by testing a large number of negative samples. Specifically, the average MFI value of the negative samples plus three times the standard deviation was considered to be the threshold for the target. Forty SPF negative samples were tested to calculate the cutoff value. As shown in Table 4, the cutoff value for RHDV, RRV and SV was $626.22,387.08$ and 436.52 , respectively.

\section{Repeatability of the xMAP assay}

To assess the reproducibility of the test results, parallel tests were carried out using diluted serum. The coefficient of variation (CV) for these three pathogens was less than 3\% for intra-assay comparisons and no more than $4 \%$ for inter-assay comparisons (Table 5), demonstrating the high repeatability and good stability of the xMAP assay.

\section{Comparison of the XMAP assay and ELISA}

A comparison with commercial ELISA kits (VRL Laboratories, SuZhou, China) was carried out using serial dilutions of serum from 1:100 to 1:51200. The results indicated that the sensitivity of the newly developed XMAP assay was similar to that of the commercial ELISA kits for antibodies detection (Table 6).
Fig. 2 The specificity of the multiplex xMAP asay. RHDV: rabbit hemorrhagic virus positive serum; SV: sendai virus positive serum; RRV: rabbit rotavirus positive serum; $\mathrm{RCoV}$ : rabbit coronavirus positive serum; E.cun: encephalitozoon cuniculi positive serum; NC: negative control; Blank: blank control
Table 4 The detection results obtained with 40 SPF negative serum samples

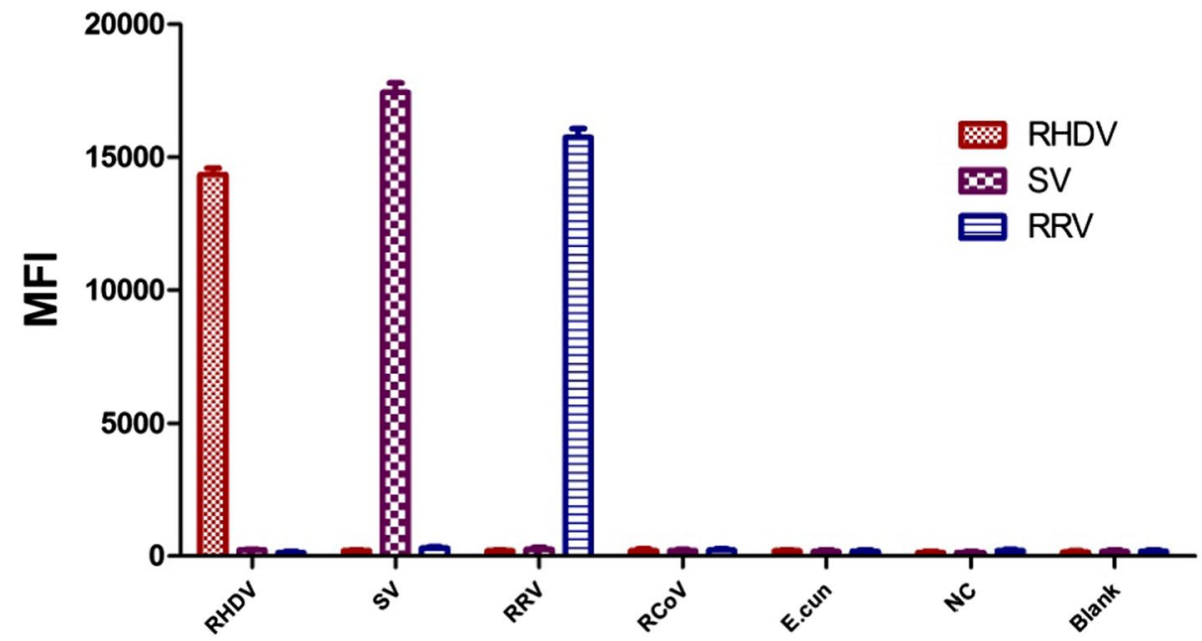

\begin{tabular}{|c|c|c|c|c|c|c|c|c|c|c|c|c|c|c|c|}
\hline \multirow{3}{*}{$\begin{array}{l}\text { Sample } \\
\text { SPF negative serum }\end{array}$} & \multicolumn{15}{|c|}{ MFI value } \\
\hline & \multicolumn{5}{|c|}{ RHDV } & \multicolumn{5}{|l|}{ SV } & \multicolumn{5}{|l|}{ RRV } \\
\hline & 210 & 317 & 221 & 107 & 173 & 58 & 264 & 110 & 160 & 43 & 468 & 195 & 111 & 148 & 138 \\
\hline & 242 & 319 & 264 & 121 & 185 & 152 & 173 & 150 & 173 & 93 & 82 & 143 & 132 & 205 & 77 \\
\hline & 234 & 145 & 183 & 199 & 207 & 185 & 140 & 220 & 75 & 184 & 201 & 75 & 202 & 98 & 154 \\
\hline & 137 & 126 & 258 & 174 & 188 & 123.5 & 186 & 322 & 107 & 203 & 174 & 207 & 285 & 118 & 221 \\
\hline & 331 & 305 & 272 & 128 & 145 & 234 & 137 & 139 & 93 & 67 & 164 & 185 & 148 & 79 & 79 \\
\hline & 285 & 48 & 194 & 102 & 128 & 150 & 63 & 218 & 143 & 184 & 89 & 94 & 189 & 121 & 172 \\
\hline & 178 & 139 & 112 & 148 & 167 & 232 & 302 & 134 & 92 & 253 & 221 & 287 & 112 & 68 & 201 \\
\hline & 143 & 154 & 166 & 176 & 123 & 225 & 113 & 88 & 372 & 243 & 264 & 195 & 94 & 331 & 198 \\
\hline Average & \multicolumn{5}{|c|}{186.34} & \multicolumn{5}{|l|}{163.32} & \multicolumn{5}{|c|}{172.63} \\
\hline SD & \multicolumn{5}{|c|}{67.21} & \multicolumn{5}{|l|}{76.41} & \multicolumn{5}{|c|}{87.96} \\
\hline Cutoff & \multicolumn{5}{|c|}{626.22} & \multicolumn{5}{|l|}{387.08} & \multicolumn{5}{|c|}{436.52} \\
\hline
\end{tabular}


Table 5 The repeatability of the xMAP assay at different serum concentrations

\begin{tabular}{|c|c|c|c|c|c|c|c|c|c|}
\hline \multirow[t]{2}{*}{ Pathogen } & \multirow[t]{2}{*}{ Concentration } & \multicolumn{3}{|c|}{ Intra-assay/MFI } & \multirow[t]{2}{*}{$\mathrm{CV}(\%)$} & \multicolumn{3}{|c|}{ Inter-assay/MFI } & \multirow[t]{2}{*}{$\mathrm{CV}(\%)$} \\
\hline & & 1 & 2 & 3 & & 1 & 2 & 3 & \\
\hline \multirow[t]{2}{*}{ RHDV } & $1: 400$ & 11409 & 11206 & 11613 & 2.54 & 11871 & 11435 & 11312 & 3.3 \\
\hline & $1: 3200$ & 3472 & 3271 & 3071 & 2.8 & 3286 & 3465 & 3217 & 3.5 \\
\hline \multirow[t]{2}{*}{ SV } & $1: 400$ & 11536 & 11348 & 10997 & 2.6 & 12174 & 11853 & 12053 & 3.2 \\
\hline & $1: 3200$ & 3114 & 3167 & 3072 & 2.73 & 3295 & 3134 & 3184 & 2.6 \\
\hline \multirow[t]{2}{*}{ RRV } & $1: 400$ & 14587 & 14324 & 14097 & 1.8 & 14184 & 13996 & 14233 & 2.2 \\
\hline & $1: 3200$ & 2564 & 2465 & 2532 & 2.15 & 2651 & 2438 & 2364 & 2.72 \\
\hline
\end{tabular}

Table 6 Comparison of xMAP and ELISA sensitivity

\begin{tabular}{|c|c|c|c|c|c|c|c|}
\hline \multirow[t]{2}{*}{ Sample } & \multirow{2}{*}{$\begin{array}{l}\text { Serum con- } \\
\text { centration }\end{array}$} & \multicolumn{2}{|l|}{ RHDV } & \multicolumn{2}{|l|}{ SV } & \multicolumn{2}{|l|}{ RRV } \\
\hline & & xMPA (MFI) & ELISA (OD) & xMPA (MFI) & ELISA (OD) & xMPA (MFI) & ELISA (OD) \\
\hline \multirow[t]{9}{*}{ Positive serum } & $1: 100$ & 15076 & 2.7056 & 15334 & 3.1220 & 21980 & 2.3301 \\
\hline & $1: 400$ & 11410 & 2.1496 & 11563 & 2.6446 & 14098 & 1.7876 \\
\hline & $1: 800$ & 8015 & 1.6192 & 8009 & 2.2449 & 8565 & 1.5623 \\
\hline & $1: 1600$ & 6740 & 1.2326 & 5220 & 1.8729 & 5347 & 1.4383 \\
\hline & $1: 3200$ & 3272 & 0.7784 & 3114 & 1.3109 & 2465 & 1.1679 \\
\hline & $1: 6400$ & 2178 & 0.5674 & 2034 & 0.8275 & 1544 & 1.0443 \\
\hline & $1: 12800$ & 805 & 0.3301 & 1084 & 0.4556 & 1053 & 0.8495 \\
\hline & $1: 25600$ & 363 & 0.2064 & 232 & 0.2684 & 498 & 0.5588 \\
\hline & $1: 51200$ & - & - & - & - & 354 & 0.3254 \\
\hline Negative serum & - & 149 & 0.1512 & 118 & 0.1658 & 201 & 0.2134 \\
\hline Blank & - & 126 & 0.1145 & 124 & 0.1212 & 165 & 0.2122 \\
\hline Cutoff & - & 626.22 & 0.3000 & 387.08 & 0.3000 & 436.5 & 0.3000 \\
\hline
\end{tabular}

\section{Discussion}

Table 7 Comparison of xMAP and ELISA for testing of clinical samples

\begin{tabular}{lllll}
\hline Pathogen & Method & $\begin{array}{l}\text { Positive } \\
\text { samples }\end{array}$ & $\begin{array}{l}\text { Negative } \\
\text { samples }\end{array}$ & Total coincidence \\
\hline RHDV & xMAP & 52 & 0 & $100 \%$ \\
& ELISA & 52 & 0 & \\
SV & xMAP & 18 & 34 & $100 \%$ \\
& ELISA & 18 & 34 & \\
RRV & xMAP & 47 & 5 & $100 \%$ \\
& ELISA & 47 & 5 & \\
\hline
\end{tabular}

\section{Testing of clinical samples}

Fifty-two clinical samples were tested using both the xMAP assay and ELISA kits. All the samples that were tested were positive for RHDV by both methods, while only 18 samples were positive for SV and 47 samples were positive for RRV. The two methods shared $100 \%$ coincidence when used for testing clinical samples (Table 7).
ELISA is widely used in pathogen diagnosis, and commercial ELISA kits are available for detection of antibodies against RHDV, SV and RRV. Despite the fact that ELISA is an ultrasensitive method due to the use of enzymes and chemiluminescent substrates, it is labor-intensive, especially when dealing with a large number of samples with more than one detection target. The Luminex microsphere system was invented to meet analytical needs for rapid and sensitive high-throughput detection. By changing the staining ratio of the microspheres, hundreds of targets can be identified in a single reaction. In the last few years, there have been several reports describing the application of Luminex technology (xMAP/xTAG) in veterinary science [17-19]. However, most of the applications were for the diagnosis of pathogens in birds or laboratory animals, but not rabbits. Although a Luminex xTAG assay has been developed for detection of nucleic acids of pathogens in rabbits [20], there is a strong demand for an XMAP assay for antibody detection in rabbits because antibody surveillance is vital to the control of diseases. 
In this study, a sensitive and specific xMAP assay was developed for surveillance of antibodies against RHDV, SV and RRV. Typically, the use of whole viral lysates results in a higher level of sensitivity [21]. However, the lack of a suitable cell line for RHDV and the inability to isolate RRV from clinical samples make it difficult to produce viral lysates [22]. Therefore, diagnostic antigens VP60 of RHDV and VP6 of RRV were expressed in vitro and purified for use in this study.

The approximate ratio of antigen to beads recommended by the manufacturer for the coating step is $5 \mu \mathrm{g}$ per $1 \times 10^{6}$ beads. In this study, different ratios were tested, and the one yielding the highest positive MFI value accompanied by the lowest negative MFI value was defined as the optimal antigen concentration. The optimal ratio was $10 \mu \mathrm{g}$ per $1 \times 10^{6}$ beads for RHDV and $30 \mu \mathrm{g}$ per $1 \times 10^{6}$ beads for both SV and RRV.

When compared with commercial ELISA kits, both RHDV and SV showed a similar detection capacity. With RRV, the limit of detection (LOD) was 1:25600, which was two times higher than that of ELISA (1:51200). The diagnostic antigen used in these two methods might contribute to subtle difference in the results. As discussed previously, the main advantage of using whole viral lysates is the large number of protein targets that can be detected, thus allowing a high level of sensitivity. Accordingly, the commercial ELISA kits coated with whole viral lysates showed higher sensitivity than the XMAP assay. However, high sensitivity can also increase the risk of false positive results. To avoid a false negative/positive result, samples should be rechecked to ensure the accuracy of the assay when the sample's MFI is near the cutoff value. ELISA or nucleic acid detection should be done when necessary.

Our data show that the multiplex xMAP assay is highly specific, and we did not observe any cross-reaction with irrelevant targets. The coefficient of variation for intra-assay and inter-assay comparisons was less than $4 \%$, indicating the good repeatability and stability of the xMAP assay.

Although the LOD for RRV is somewhat higher with the xMAP assay than with the commercial ELISA kit, it is sufficient for testing clinical samples and $100 \%$ coincidence was observed when testing 52 samples. Taking all of these considerations into account, the newly developed multiplex xMAP assay is a viable alternative for conventional monitoring of antibodies in rabbits. The primary advantage of xMAP is that the coating microspheres do not interfere with each other, potentially allowing the existing XMAP assay to be expanded further as needed.

In summary, a novel multiplex xMAP assay for simultaneous detection of antibodies against RHDV, SV and RRV was established and evaluated. This assay is cost-effective and labor-saving and is therefore a promising tool for monitoring of antibodies in rabbits.
Acknowledgements The experiments were conceived and designed by YZ, RH and MLC. The experiments were performed by MLW, FC and YJZ. The samples were collected by BHH, YXL and LX. The data were analysed by LM and FJX. The manuscript was prepared by MLW and PJG.

Funding This work was supported by the Science and Technology Planning Project of Guangdong Province, China (nos. 2017B030314171; 2017A070702001; 2018B030317001).

\section{Compliance with ethical standards}

Conflict of interest All the authors declare that they do not have conflicts of interest.

\section{References}

1. Peng X, Knouse JA, Hernon KM (2015) Rabbit models for studying human infectious diseases. Comp Med 65(6):499-507

2. Fan J, Kitajima S, Watanabe T, Xu J, Zhang J, Liu E, Chen YE (2015) Rabbit models for the study of human atherosclerosis: from pathophysiological mechanisms to translational medicine. Pharmacol Ther 146:104-119. https://doi.org/10.1016/j.pharmthera .2014.09.009

3. Tang C, Zhang Q, Li X, Fan N, Yang Y, Quan L, Lai L (2014) Targeted modification of CCR5 gene in rabbits by TALEN. Yi chuan (Hereditas) 36(4):360-368

4. Cabore RN, Pierard D, Huygen K (2016) A Belgian serosurveillance/seroprevalence study of diphtheria, tetanus and pertussis using a Luminex xMAP technology-based pentaplex. Vaccines. https://doi.org/10.3390/vaccines4020016

5. Liu J, Kerr PJ, Strive T (2012) A sensitive and specific blocking ELISA for the detection of rabbit calicivirus RCV-A1 antibodies. Virol J 9:182. https://doi.org/10.1186/1743-422X-9-182

6. Parker JC, O'Beirne AJ, Collins MJ Jr (1979) Sensitivity of enzyme-linked immunosorbent assay, complement fixation, and hemagglutination inhibition serological tests for detection of Sendai virus antibody in laboratory mice. J Clin Microbiol 9(3):444-447

7. Houser B (2012) Bio-Rad's Bio-Plex(R) suspension array system, xMAP technology overview. Arch Physiol Biochem 118(4):192196. https://doi.org/10.3109/13813455.2012.705301

8. Baker HN, Murphy R, Lopez E, Garcia C (2012) Conversion of a capture ELISA to a Luminex xMAP assay using a multiplex antibody screening method. J Vis Exp JoVE. https://doi. org/10.3791/4084

9. Reslova N, Michna V, Kasny M, Mikel P, Kralik P (2017) xMAP technology: applications in detection of pathogens. Front Microbiol 8:55. https://doi.org/10.3389/fmicb.2017.00055

10. Laamiri N, Fallgren P, Zohari S, Ben Ali J, Ghram A, Leijon M, Hmila I (2016) Accurate detection of avian respiratory viruses by use of multiplex PCR-based Luminex suspension microarray assay. J Clin Microbiol 54(11):2716-2725. https://doi. org/10.1128/JCM.00610-16

11. Rausch TK, Schillert A, Ziegler A, Luking A, Zucht HD, SchulzKnappe $P$ (2016) Comparison of pre-processing methods for multiplex bead-based immunoassays. BMC Genom 17(1):601. https ://doi.org/10.1186/s12864-016-2888-7

12. Bovers M, Diaz MR, Hagen F, Spanjaard L, Duim B, Visser CE, Hoogveld HL, Scharringa J, Hoepelman IM, Fell JW, Boekhout $\mathrm{T}$ (2007) Identification of genotypically diverse Cryptococcus neoformans and Cryptococcus gattii isolates by Luminex xMAP 
technology. J Clin Microbiol 45(6):1874-1883. https://doi. org/10.1128/JCM.00223-07

13. Wang H, Cong F, Guan J, Xiao L, Zhu Y, Lian Y, Huang R, Chen M, Guo P (2018) Development of a sensitive and specific xMAP assay for detection of antibodies against infectious laryngotracheitis and bronchitis viruses. Virol J 15(1):146. https://doi. org/10.1186/s12985-018-1048-x

14. Gu AD, Lu LX, Xie YB, Chen LZ, Feng QS, Kang T, Jia WH, Zeng YX (2009) Clinical values of multiple Epstein-Barr virus (EBV) serological biomarkers detected by xMAP technology. J Transl Med 7:73. https://doi.org/10.1186/1479-5876-7-73

15. Heming JD, Huffman JB, Jones LM, Homa FL (2014) Isolation and characterization of the herpes simplex virus 1 terminase complex. J Virol 88(1):225-236. https://doi.org/10.1128/JVI.02632-13

16. Karanikola SN, Krucken J, Ramunke S, de Waal T, Hoglund J, Charlier J, Weber C, Muller E, Kowalczyk SJ, Kaba J, von Samson-Himmelstjerna G, Demeler J (2015) Development of a multiplex fluorescence immunological assay for the simultaneous detection of antibodies against Cooperia oncophora, Dictyocaulus viviparus and Fasciola hepatica in cattle. Parasites Vectors 8:335. https://doi.org/10.1186/s13071-015-0924-0

17. Xu L, Jiang X, Zhu Y, Duan Y, Huang T, Huang Z, Liu C, Xu $\mathrm{B}$, Xie Z (2018) A multiplex asymmetric reverse transcriptionPCR assay combined with an electrochemical DNA sensor for simultaneously detecting and subtyping influenza A viruses. Front Microbiol 9:1405. https://doi.org/10.3389/fmicb.2018.01405

18. Cong F, Zhu Y, Liu X, Li X, Chen M, Huang R, Guo P (2018) Development of an XTAG-multiplex PCR array for the detection of four avian respiratory viruses. Mol Cell Probes 37:1-5. https ://doi.org/10.1016/j.mcp.2017.10.002

19. Xu F, Yuan W, Zhang T, Zhu Y, Lian Y, Zhang Y, Huang R, Guo $P$ (2017) Simultaneous detection of 4 prototypic rat parvoviruses using the Luminex xTAG assay in laboratory animal health monitoring. J Virol Methods 248:61-65. https://doi.org/10.1016/j.jviro met.2017.05.017

20. Wu M, Zhu Y, Cong F, Rao D, Yuan W, Wang J, Huang B, Lian Y, Zhang Y, Huang R, Guo P (2018) Rapid detection of three rabbit pathogens by use of the Luminex X-TAG assay. BMC Vet Res 14(1):127. https://doi.org/10.1186/s12917-018-1438-8

21. Ayouba A, Toure A, Butel C, Keita AK, Binetruy F, Sow MS, Foulongne V, Delaporte E, Peeters M (2017) Development of a sensitive and specific serological assay based on Luminex technology for detection of antibodies to Zaire ebolavirus. J Clin Microbiol 55(1):165-176. https://doi.org/10.1128/JCM.01979-16

22. Zhu J, Wang B, Miao Q, Tan Y, Li C, Chen Z, Guo H, Liu G (2015) Viral genome-linked protein (VPg) is essential for translation initiation of rabbit hemorrhagic disease virus (RHDV). PLoS One 10(11):e0143467. https://doi.org/10.1371/journal.pone.01434 67

Publisher's Note Springer Nature remains neutral with regard to jurisdictional claims in published maps and institutional affiliations. 